\title{
Estudo e Considerações sobre a Revisão da NBR 13755:2017 com Ênfase na Gestão de Risco Proposta pela ISO 9001:2015
}

Study and Considerations on the Revision of NBR 13755/2017 With Emphasis on Risk Management Proposed by ISO 9001/2015

Bárbara Cecilia Costa Araújo 1 (1) orcid.org/0000-0001-9619-2032

Ana de Fátima Braga Barbosa 1 (b) orcid.org/0000-0001-9747-4939

${ }^{1}$ Pós-graduação em Gestão da Qualidade e Produtividade, Escola Politécnica de Pernambuco, UPE, Pernambuco, Recife, Brasil.

E-mail do autor principal: Bárbara Cecilia Costa Araújo babih_cca@hotmail.com

\section{RESUMO}

O gerenciamento de riscos representa uma importante ferramenta de gestão entre as empresas que desejam se destacar dentro do seu negócio. O objetivo deste trabalho é apresentar os principais requisitos da NBR 13755 - Revestimentos cerâmicos de fachadas com utilização de argamassa colante, atualizada em 2017, que tiveram influência da gestão de risco proposta pela ISO 9001:2015 como forma de prevenir as falhas ou manifestações patológicas de maior incidência nas fachadas, trazendo melhorias internas às organizações e vantagens competitivas às construtoras que optaram por sua implantação. Com base na pesquisa bibliográfica realizada, ficou evidente que a NBR 13755:2017 teve sua atualização inspirada na mentalidade de risco e na abordagem de ameaças capazes de alterar o desempenho do revestimento externo, traçando ações preventivas que garantam às empresas produtos e serviços que cumpram sua vida útil e satisfaçam a necessidade dos clientes. Este trabalho contribui para a consolidação da prática da gestão de risco em diferentes negócios, inclusive na construção civil, e para a fomentação da cultura de condutas preventivas. A pesquisa ainda abre precedentes para estudos mais amplos sobre a eficácia da NBR 13755:2017 e de seus critérios preventivos.

PALAVRAS-CHAVE: NBR ISO 9001; NBR 13755; Gestão de risco; Construção civil.

\section{ABSTRACT}

Risk management is an important management tool among companies wishing to excel in their activities. The objective of this project is to present the main requirements of NBR 13755 - Ceramic coatings of facades with the use of adhesive mortar, updated in 2017, which was influenced by risk management initiatives proposed by ISO 9001: 2015 as a way to prevent failures or pathological manifestations of greater incidence in the façades, bringing internal improvements to the organizations and competitive advantages to the builders that opted for its implantation. Based on the bibliographical research carried out, it was evident that NBR 13755: 2017 was updated based on a risk driven mentality and on an analysis of threats capable of altering the performance of the external coating, tracing preventive measures guaranteeing companies their products and services fulfill their service life and meet customer's needs. This paper contributes to the consolidation of the practice of risk management in different fields, including civil construction, and to fostering the culture of preventive behaviors. The research also opens precedents for further studies on the efficacy of NBR 13755: 2017 and its preventive criteria.

KEY-WORDS: NBR ISO 9001; NBR 13755 ABNT; Risk management; Construction. 


\section{INTRODUÇÃO}

No cenário atual da economia brasileira, as empresas vêm atuando em um ambiente com constantes inovações tecnológicas e mudanças dos padrões de exigência dos consumidores. Cada vez mais, as organizações se desenvolvem em função de variados parâmetros para garantir sua competitividade e sobrevivência no mercado: concorrência, legislação, tecnologia, demandas de mercado, aumento da consciência do consumidor, globalização, crises econômicas e políticas, entre outros [1]. Diante de tantos requisitos e na busca por novos clientes, é clara a necessidade das empresas na potencialização de sua excelência. A gestão da qualidade representa uma importante ferramenta com capacidade de apoiar este processo, gerando vantagens competitivas para diferenciação positiva dentro do contexto mundial.

No ramo da construção civil, setor com grande desperdício de materiais, mão de obra desqualificada e grande geração de resíduos sólidos [2], as buscas por certificações na área da qualidade são crescentes. Este fato se deve às exigências de consumidores mais esclarecidos e rigorosos na escolha de produtos e/ou serviços, por consciência social e moral e pela percepção dos benefícios trazidos pelos sistemas de gestão.

A norma ISO 9001, que aborda os requisitos para a implantação de um sistema de gestão da qualidade, é a mais conhecida e utilizada no mundo, estando implantada em cerca de um milhão de empresas e organizações, em mais de 170 países [3]. Seu conteúdo se mantém sempre revisado, assegurando sua adequação às novas exigências do mercado. Sua primeira versão foi publicada em 1987, com revisões em 1994, 2000, 2008 e 2015 (revisão mais atual). O mesmo ocorreu com a NBR 13755 - Revestimento de paredes externas e fachadas com placas cerâmicas e com utilização de argamassa colante, com sua primeira versão publicada em 1996 e revisada recentemente, em 2017, pela Associação Brasileira de Normas Técnicas (ABNT).

A revisão da NBR 13755 trouxe a inclusão de aspectos relacionados ao projeto de revestimentos externos e maiores detalhes a respeito do controle tecnológico e inspeção. É possível relacionar tal revisão com a mentalidade e gestão de risco abordada pela ISO 9001:2015, a partir do momento que seus requisitos são atualizados com o objetivo de prevenir ou minimizar possíveis riscos às futuras edificações, refletindo no fornecimento de produtos ou serviços de modo eficaz ao longo de sua vida útil e trazendo benefícios e melhorias para a construção civil.

\section{OBJETIVOS}

\subsection{Objetivo Geral}

Analisar a revisão da NBR 13755:2017 com ênfase na gestão de risco sugerida pela ISO 9001:2015, identificando os novos critérios da norma que podem vir a reduzir as possíveis falhas ou manifestações patológicas nas construções.

\subsection{Objetivos Específicos}

- Evidenciar a possibilidade do uso da gestão de risco em outras esferas além do sistema de gestão da qualidade, como na execução dos revestimentos externos das edificações;

- Enfatizar a importância da abordagem da mentalidade de risco em todo e qualquer negócio como forma de melhoria;

- Apresentar os benefícios de implantação da NBR 13755:2017 no meio da construção civil.

\section{FUNDAMENTAÇÃO TEÓRICA EVOLUÇÃO DA NORMA ISO 9001}

A qualidade não é um conceito atual como muitos podem pensar. Sua aplicação sempre esteve presente nas relações comerciais como uma poderosa estratégia para se atingir os resultados esperados.

Após a Segunda Guerra Mundial (1939-1945), por exemplo, os japoneses viram na industrialização uma maneira de evitar sua extinção, importando matérias- primas básicas escassas em seu território e exportando produtos manufaturados com qualidade, preço competitivo e fabricação eficiente. Para fortalecer a qualidade de suas mercadorias, o país contou, inclusive, com a ajuda de grandes pensadores e mestres no desenvolvimento de normas de qualidade que padronizassem o seu sistema de produção, a exemplo de Deming e Juran [1].

Ao longo dos anos, a qualidade foi ganhando importância, principalmente no meio industrial. Com o aquecimento da economia, as empresas 
sentiram ainda mais a necessidade de melhorar os seus processos para aumentar sua produtividade e qualidade, e assim sobreviver no mercado.

Em 1946, representantes de 25 países reuniram- se em Londres para a criação de uma organização internacional que tivesse como objetivo facilitar a coordenação global e unificação dos padrões industriais. Surgia a ISO International Organization for Standardization, com sede em Genebra (Suíça) e cujas operações foram iniciadas em 23 de fevereiro de 1947. Atualmente, sua principal função é normatizar produtos e serviços para que a qualidade destes seja permanentemente melhorada [4].

Em 1987 a ISO adotou a BS 5750 (norma britânica) como norma padrão internacional de gestão, onde além de especificar como se produzir, abordava também o gerenciamento do processo de produção. A BS 5750 tornou-se a primeira versão da ISO 9001, que tem como finalidade principal definir os requisitos para colocar em vigor o sistema de gestão da qualidade, ajudando as empresas a aumentarem sua eficiência e a satisfação dos clientes através de processos para melhoria do sistema e para garantia da conformidade com os requisitos do cliente e com os requisitos legais.

A primeira versão da ABNT ISO 9001 (1987) tinha o enfoque principal na garantia da qualidade e na elaboração da Política da Qualidade pela alta direção, com exigência de um grande número de documentos e procedimentos, o que culminou na burocratização do processo.

Em 1994, a ISO 9001 ganhou uma nova versão, mas sem muitas modificações em relação à de 1987. A principal mudança foi a transformação para o enfoque preventivo, com a inclusão do requisito ação preventiva, ao invés de inspeções ao produto final, exigindo evidências de conformidade com procedimentos documentados [1].

A entrada no novo século e a globalização trouxeram mudanças em todo o contexto econômico mundial, inclusive no Brasil. No ano 2000, a ISO 9001 teve o seu conteúdo revisado, adaptando-se ao cenário da época, com importantes mudanças estruturais e a aplicação dos 8 princípios da qualidade: foco no cliente, liderança, envolvimento das pessoas, abordagem por processos, abordagem sistêmica de gestão, melhoria contínua, abordagem factual para a tomada de decisões e benefícios mútuos nas relações com fornecedores. $O$ conceito de qualidade passou a ser fundamentado no gerenciamento contínuo do processo com base no ciclo PDCA (Plan - Planejar, Do - Executar, Check - Verificar, Action - Agir) e na diferenciação dos clientes internos e externos.

Entre 2008 e 2009 o Brasil enfrentou um período de instabilidade financeira, reflexo da crise econômica mundial [5]. Em função disso, o número de certificações ISO 9001 decresceram, como mostrado na Figura 1.

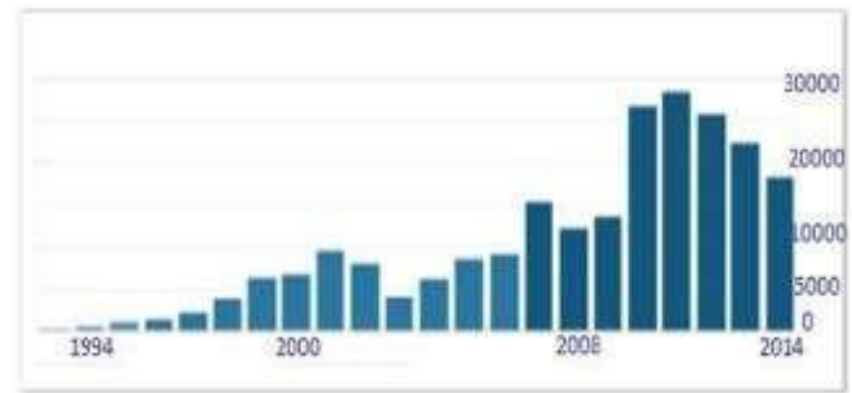

Figura 1: Evolução das empresas com certificação ISO 9001 no Brasil.

Fonte: [5].

Diante de uma nova conjuntura e após 8 anos de uso, a ISO 9001:2008 foi publicada. As alterações foram mínimas, apenas ajustes e esclarecimentos de tradução com o intuito de facilitar o entendimento, interpretação e aplicação da norma.

A última versão da ISO 9001 foi lançada no Brasil em setembro de 2015, pela ABNT, trazendo mudanças expressivas em sua estrutura, terminologias, conceitos e na própria gestão em si. O PDCA e o enfoque na gestão da qualidade foram mantidos, enquanto que a imagem do representante da qualidade foi abolida definitivamente para dar espaço a liderança em todos os níveis organizacionais. O foco na satisfação do cliente passou a ser transferido para a satisfação de toda e qualquer parte interessada (stakeholders) e se tornaram 7 os princípios da qualidade: foco no cliente, liderança, engajamento das pessoas, abordagem por processos, melhoria, tomada de decisão baseada em evidências e gestão das relações.

O Anexo SL foi uma das novidades da ISO 9001:2015. Este documento foi desenvolvido para melhorar a compatibilidade com outras normas de gestão, definindo uma estrutura de alto nível, 
textos básicos e nomenclaturas idênticas para garantir que as futuras normas ISO para sistemas de gestão tenham um mesmo formato. Outra grande mudança que merece destaque, base para esta pesquisa, foi a abordagem da mentalidade e gestão de riscos, que se apresenta em substituição às ações preventivas oriundas das não conformidades potenciais.

A Figura 2 apresenta, de forma sucinta, a evolução da ABNT NBR ISO 9001, que vem se tornando cada vez mais um bom marketing para as organizações certificadas nesta norma, ajudando a melhorar o seu desempenho global e a imagem da marca perante os seus clientes.

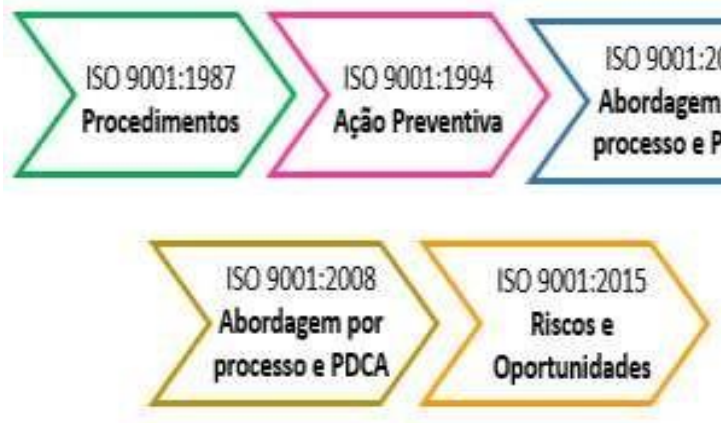

Figura 2: Evolução da ISO 9001.

Fonte: [4].

\section{ISO 9001/2015: FOCO NA MENTALIDADE E GESTÃO DE RISCO}

Conforme a NBR ISO 31000 [6], risco corresponde ao efeito da incerteza sobre os objetivos da organização. Por muitas vezes, o risco é expresso em termos de uma combinação de consequências de um evento e a probabilidade de ocorrência associada.

A percepção do risco muda conforme o ambiente no qual a pessoa está inserida. No contexto atual da economia, onde ocorrem frequentes inovações tecnológicas e aumento da competitividade, a gestão de risco tornou-se uma das demandas mais urgentes dentro das organizações, com a finalidade de guiar questões econômicas, implementar novas tecnologias e manter-se no mercado.

Atenta a esse fato, a ISO 9001:2015 promoveu o uso da mentalidade de risco como forma de melhor gerir as empresas, apoiando o fornecimento de produtos e serviços de qualidade a curto e longo prazo que contribuam para o seu diferencial competitivo.

O conceito de mentalidade de risco estava implícito nas versões anteriores da ISO 9001, através de ações preventivas para eliminação de não conformidades potenciais. Porém, a versão 2015 trouxe, em seus itens 6.1 e 10.1 , requisitos que exigem o planejamento e implementação de ações para abordar os riscos e oportunidades dentro de uma organização, estabelecendo uma base para o aumento da eficácia do sistema de gestão da qualidade, melhoria dos resultados e prevenção dos efeitos negativos [7].

A visão estratégica da norma expandiu o olhar preventivo ao longo de todos os processos do negócio, e não apenas na fase final de produção, permitindo que as organizações sejam capazes de prever os fatores que podem causar desvios em relação aos resultados planejados, colocando em prática controles preventivos para minimizar efeitos indesejáveis e maximizar o aproveitamento das oportunidades que podem surgir [7].

A principal abordagem da gestão de risco vem da ISO 31000, publicada em 2009, com o fornecimento dos princípios e das diretrizes genéricas para implantação da gerência dos riscos dentro de uma empresa. Segunda esta norma, o gerenciamento de risco é um conjunto de atividades coordenadas para dirigir e controlar uma organização no que se refere aos riscos [6].

De forma genérica, a ferramenta consiste, inicialmente, no estabelecimento do contexto (interno e externo) onde a organização está imersa e na identificação das partes interessadas que contribuem para a sustentabilidade do seu negócio. Após isso, os riscos são levantados, analisados (classificados como ameaças ou oportunidades) e avaliados de acordo com a sua probabilidade e impacto, para que possam ser traçadas as ações preventivas diante dos diferentes cenários, positivos ou negativos.

Estas ações preventivas podem optar por evitar o risco, assumir o risco para perseguir uma oportunidade, eliminar a fonte de risco, mudar a probabilidade ou as consequências, compartilhar o risco ou decidir, com base em informação, reter o risco [7]. Toda esta sistemática deve ser rotineiramente monitorada e analisada para avaliação da eficácia da gestão de risco e possíveis melhorias, conforme esquematizado na Figura 3. 


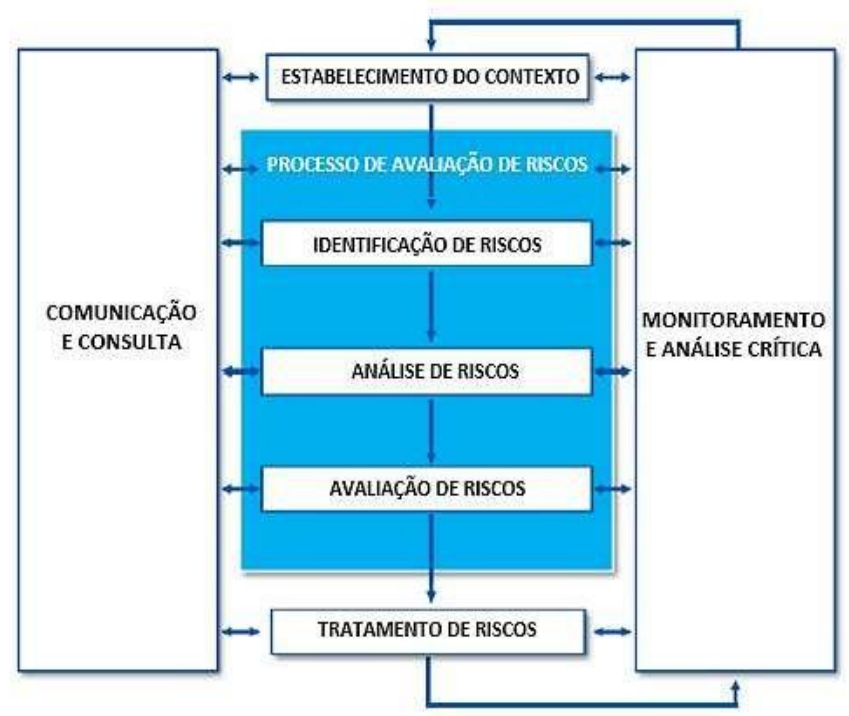

Figura 3: Processo para gerenciar riscos. Fonte: [6].

A ISO 9001:2015 não estabelece que a avaliação do risco deva ser baseada apenas em análises quantitativas ou qualitativas. Desta forma, a organização define qual a melhor maneira para avaliar os seus riscos [3].

O gerenciamento do risco não deve ser privilégio do sistema de gestão da qualidade. Convém que este plano de gestão seja incorporado em todas as práticas e processos empresariais de todo e qualquer tipo de segmento, de forma que seja preventivo, pertinente, eficaz e eficiente.

\section{NBR 13755/2017: UM NOVO OLHAR DA CONSTRUÇÃO CIVIL}

São inúmeras as especificidades na construção civil quando comparada à indústria. A diversidade de insumos utilizados em cada serviço pode, de alguma forma, alterar ou comprometer o desempenho global dos sistemas [8], através do surgimento de manifestações patológicas. $\mathrm{Na}$ execução dos revestimentos verticais externos das edificações não é diferente.

A incidência de sintomas patológicos é bastante significativa nos edifícios do mercado brasileiro. Pezzato [9] cita uma pesquisa realizada por Esquível em 2002, onde 33\% das edificações analisadas na cidade de São Paulo, com revestimento cerâmico em fachada, apresentavam algum tipo de anomalia. As principais ocorrências, segundo Uliana et al apud Pacheco [10], são os desplacamentos do revestimento, fissuras e trincas, eflorescência, manchamento, deterioração do revestimento e corrosão, conforme observados nas Figuras 4 e 5 a seguir.

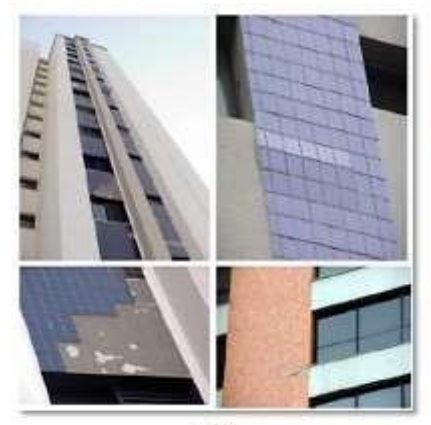

(a)

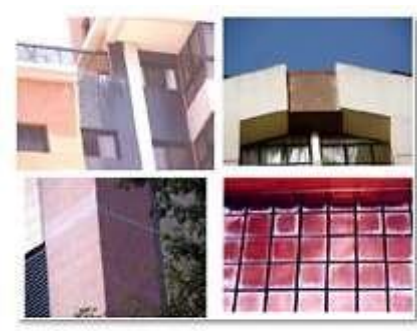

(b)
Figura 4: (a) Fachada com descolamento de placas cerâmicas; (b) Eflorescência em revestimentos cerâmicos de fachada.

Fonte: [11].

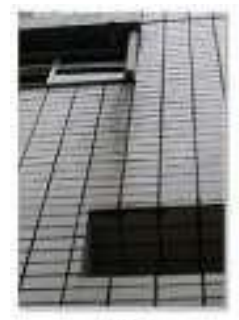

(a)

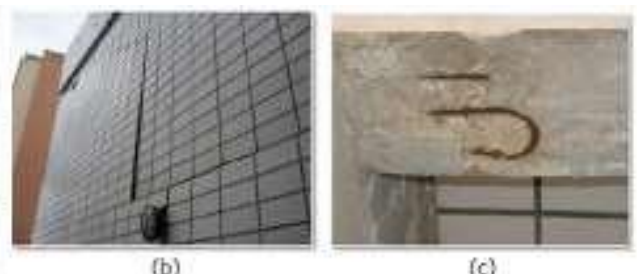

(c)
Figura 5: (a) Fachada com manchamentos; (b) Detalhe de trinca; (c) Destacamento por expansão de ferragem exposta.

Fonte: [12].

As falhas citadas são capazes de trazer prejuízos para a fachada, como a redução da vida útil do edifício, além de representar fatores de risco à segurança das pessoas que circulam em suas proximidades. Atualmente, o desplacamento cerâmico é um dos fenômenos mais estudados por apresentar o maior grau de recorrência e ser a manifestação mais perigosa devido aos riscos de queda de peças cerâmicas, que podem provocar danos materiais e/ou humanos.

Os problemas em fachadas podem originar-se devido a diversas causas, em função da grande complexidade dos sistemas envolvidos durante o processo construtivo, que atuam juntas ou separadamente. Pires et al [13] relaciona na Tabela 1 as principais doenças encontradas nos revestimentos externos e seus possíveis agentes. 
Tabela 1: Manifestações patológicas e suas causas.

\begin{tabular}{|c|c|}
\hline Manifestações patológicas & Causas \\
\hline $\begin{array}{l}\text { Manifestações causadas por } \\
\text { umidade (mofo, bolor, } \\
\text { eflorescências, vesículas) }\end{array}$ & $\begin{array}{l}\text { - Infiltração } \\
\text { - Condensação } \\
\text { - Processos construtivos } \\
\text { inacabados } \\
\text { - Capilaridade } \\
\text { - Percolação } \\
\text { - Absorção } \\
\text { - Ausência de dreno, } \\
\text { pingadeira ou calha }\end{array}$ \\
\hline Fissuras, trincas e rachaduras & $\begin{array}{l}\text { - Recalque } \\
\text { - Movimentos estruturais } \\
\text { - Contração } \\
\text { - Esforços excessivos } \\
\text { - Dilatação térmica e } \\
\text { higrométrica }\end{array}$ \\
\hline Descolamento do revestimento & $\begin{array}{l}\text { - Movimentos estruturais } \\
\text { - Dilatação térmica } \\
\text { - Baixa aderência } \\
\text { - Materiais inadequados } \\
\text { - Ações do meio } \\
\text { - Falhas de execução } \\
\text { - Baixa resistência do } \\
\text { revestimento }\end{array}$ \\
\hline Manchas & $\begin{array}{l}\text { - Elementos construtivos } \\
\text { - Aç̃̃es do vento e chuva } \\
\text { - Poluentes atmosféricos }\end{array}$ \\
\hline
\end{tabular}

Fonte: Adaptado de [13].

Just et al [8] ainda vincula, de maneira geral, as origens para o aparecimento de manifestações patológicas nas fachadas em revestimento cerâmico com aspectos relacionados aos materiais, projeto, execução e as atividades de operação (uso e manutenção) da edificação.

Diante deste cenário, e inspirada na visão de mentalidade de risco preconizada pela ISO 9001:2015, a norma brasileira NBR 13755:2017 Revestimentos cerâmicos de fachadas e paredes externas com utilização de argamassa colante Projeto, execução, inspeção e aceitação, publicada pela Associação Brasileira de Normas Técnicas (ABNT), revisou seus requisitos, adotando ações preventivas a fim de evitar o surgimento das principais manifestações ocorridas nos revestimentos externos.

A primeira versão da NBR 13755 foi publicada em 1996, para estabelecer os critérios de execução, fiscalização e recebimento de revestimento de paredes externas com placas cerâmicas assentadas com argamassa colante específica para fachadas [14]. $O$ aspecto principal tratava apenas do procedimento executivo do revestimento externo, restringindo e tornando o documento inflexível. A evolução da NBR 13755, em 2017, trouxe mudanças que consistiram na incorporação das condições exigíveis para projeto e detalhamento do controle tecnológico neste tipo de sistema, incluindo a inspeção, além de considerações relativas aos materiais e a execução do próprio revestimento cerâmico [15], fazendo da norma uma diretriz técnica de grande utilidade no dia a dia.

Em relação aos materiais, uma das alterações mais importantes foi a especificação do uso da argamassa tipo ACIII (argamassa colante mais aderente dentre os três tipos existentes - ACI, ACII e ACIII - indicada para situações que exigem maior resistência de aderência) em toda a fachada, exceto para prédios de até 15 metros de altura em condições especiais.

A NBR 13755:1996 não definia o tipo da argamassa colante que deveria ser utilizado no revestimento externo, sendo este definido pela empresa muitas vezes em relação ao custo. Outra diretriz importante na nova versão da norma trata da mistura da argamassa colante, que agora deve ser feita de maneira mecânica, sem a possibilidade da fabricação manual, como prescrita anteriormente. Mudanças, como a permissão de até $30 \%$ da área do tardoz (verso) da placa com a presença do engobe de muratura, que corresponde ao material aplicado no tardoz das placas cerâmicas destinado a permitir a movimentação das mesmas dentro do forno sem aderir sobre os rolos no processo de queima [16], além do uso de placas cerâmicas com dimensões maiores que $400 \mathrm{~cm}^{2}$ na fachada, foram inovadoras, permitindo adequar a norma à tendência dos mais variados tipos de revestimentos.

A NBR 13755:2017 também faz referência ao tipo de rejunte a ser utilizado, ARII - Argamassa de Rejuntamento Tipo II, e a largura mínima de rejunte para placas cerâmicas tradicionais, $5 \mathrm{~mm}$, bem como para as pastilhas, de acordo com especificação do fabricante.

O aspecto de projeto abordado na versão 2017 é indispensável nos dias atuais, orientando construtoras e projetistas em diversos tópicos. $O$ PRF - Projeto de Revestimento de Fachada - deve ser desenvolvido por profissional legalmente habilitado, podendo ser subcontratado ou concebido internamente pela construtora. Neste âmbito, diversas instruções foram reforçadas e/ou 
adicionadas. Atualmente, a espessura do emboço da fachada deve ser de no mínimo $20 \mathrm{~mm}$ e no máximo $80 \mathrm{~mm}$, não podendo cada camada ultrapassar $50 \mathrm{~mm}$. Caso não seja possível atender estes requisitos, a norma intensificou a utilização de telas metálicas de reforço, agora preconizando a especificação destas e em quais situações e onde utilizá-las, de acordo com a recomendação do projetista, sejam para regiões com emboço acima de $50 \mathrm{~mm}$ ou passivas de fissuração.

É importante salientar que a especificação das telas de reforço mencionadas na norma (tela quadrada eletrosoldada $25 \times 25 \mathrm{~cm}$, com fio diâmetro $1,24 \mathrm{~mm}$ e galvanizada no mínimo $150 \mathrm{~g} / \mathrm{m}^{2}$ ) já eram pela maioria das construtoras. Este fato demonstra a adequação da norma às tecnologias recentes, abalizando os conhecimentos disseminados na área. Outro procedimento recorrente nas obras que se tornou obrigatoriedade com a norma 13755:2017 foi a realização do painel teste, que consiste na representação de um pano do revestimento externo, com as mesmas exposições a que ele será submetido ao longo de sua vida útil, para a efetuação de ensaios de resistência de aderência, onde serão avaliadas, previamente, as condições reais de execução.

A norma sugere a aplicação do painel teste com 3 meses de antecedência do início da fachada da edificação, para que, se houver necessidade, as correções possam ser realizadas ainda na fase do projeto. Os ensaios podem ser efetuados com 7, 14,21 e 28 dias com o intuito de se traçar uma curva de resistência de aderência, o que favorece a escolha dos materiais mais adequados a cada tipo de situação. A largura mínima das juntas de movimentação também passou por padronização, devendo seguir $15 \mathrm{~mm}$ de altura, e o fator de forma (relação entre altura e espessura do selante) deve variar entre $1: 1$ ou 1:2.

No que tange a execução do revestimento cerâmico, a atualização da norma traz algumas informações importantes a respeito da cura úmida da argamassa, enfatizando a importância tanto para o emboço quanto para o chapisco, principalmente para locais com temperatura acima de $30^{\circ} \mathrm{C}$. Também recomenda o umedecimento das juntas antes da aplicação do rejunte, para facilitar a sua execução e para evitar que o material perca água para o sistema. Outro ponto, também abordado, refere-se à preparação da base antes da aplicação do chapisco. Desde 1996, ano da primeira publicação da norma, a evolução do concreto ocorreu de maneira progressiva. Atualmente existem no mercado concretos com altos níveis de resistência, o que minimiza o grau de aderência da argamassa de chapisco. Buscando solucionar esta situação, a norma prevê, para bases mais lisas e pouco porosas, ou seja, níveis de resistência mais altos, a limpeza da estrutura com discos de desbaste que consigam remover a camada superficial do concreto, tornando-o mais rugoso e com maior capacidade de ligação com o chapisco. Por ser de fácil execução e baixo custo, este procedimento já era algo implantado entre as construtoras e recomendado por projetistas antes mesmo da obrigatoriedade da norma.

Em casos específicos, a versão 2017 recomenda a utilização do chapisco duplo, que corresponde a aplicação do chapisco convencional precedido do chapisco industrializado aplicado com desempenadeira sobre a base, com o intuito de aumentar o nível de aderência do sistema. Ainda, a nova revisão destaca a necessidade de um planejamento mais eficiente para cumprimento dos prazos que antecipam a execução do chapisco, emboço, cerâmica, rejunte e juntas, como forma de minimizar possíveis problemas durante a vida útil da fachada.

Por fim, o último aspecto de destaque da NBR 13755:2017 diz respeito aos procedimentos de inspeção e controle. A versão atual mantém a recomendação para o ensaio de resistência de aderência à tração direta, mas com alterações importantes. Sugere-se a realização adicional do ensaio de resistência superficial para avaliação da capacidade de suporte do emboço, realizada através do arrancamento, sem corte, de amostras circulares metálicas de $5 \mathrm{~cm}$ de diâmetro.

Em complemento a esta recomendação e buscando eliminar uma deficiência da versão anterior, a revisão atual da norma determina a amostragem dos ensaios. Tanto para o ensaio de resistência superficial quanto para o de aderência do revestimento cerâmico, define-se 12 corpos de prova a cada $2.000 \mathrm{~m}^{2}$ de fachada. Se pelo menos oito destes apresentarem resistência maior ou igual a 0,5 $\mathrm{MPa}^{1}$, o pano está aprovado. Caso o resultado de oito amostras esteja entre 0,3 e 0,5 $\mathrm{MPa}^{1}$, deve-se consultar 0 responsável pelo projeto. A área é reprovada automaticamente se menos de oito corpos de prova evidenciarem 
resistência maior ou igual a $0,3 \mathrm{MPa}^{1}$.

A situação intermediária reforça a necessidade do projetista para elaboração do PRF, visando a existência de um responsável técnico que responda por qualquer problema que venha a ocorrer no revestimento externo. Outra grande novidade que veio para reforçar as práticas já existentes em campo é a avaliação do preenchimento do tardoz da cerâmica com argamassa colante. A versão 2017 apresenta critérios de aceitação em relação a este tema. A cada $40 \mathrm{~m}^{2}$ de aplicação do revestimento externo deve ser realizada a $1^{a}$ amostragem com 0 arrancamento de duas placas recentemente assentadas. Se as duas placas obtiverem preenchimento do tardoz superior ou igual a $90 \%$, o pano está aprovado, mas se uma ou mais apresentarem resultado inferior, recomenda-se a realização de uma $2^{a}$ amostragem, agora com quatro placas.

Se nesta nova amostragem pelo menos três placas tiverem resultado satisfatório, ou seja, acima ou igual a $90 \%$ de preenchimento, o pano será aprovado. Se pelo menos três placas revelarem preenchimento superior a $80 \%$, a área deve ser aprovada e a equipe de produção retreinada. Para as demais situações o pano será reprovado, devendo-se recompor a área com uma nova aplicação do revestimento cerâmico.
Para a maioria dos tópicos abordados nesta seção, a atualização da norma ainda traz desenhos ilustrativos com maior riqueza de detalhes quando comparada à versão anterior, que contribuem para o entendimento de todo o público e minimizam possíveis dúvidas.

\section{APLICAÇÃO DA GESTÃO DE RISCO NA NBR 13755/2017}

A revisão da NBR 13755:2017 Revestimentos cerâmicos de fachadas e paredes externas com utilização de argamassa colante Projeto, execução, inspeção e aceitação, trouxe para seus usuários diretrizes importantes, incorporando critérios preventivos fruto de uma abordagem dos principais riscos incidentes nas fachadas das edificações, com o objetivo de prevenir as ameaças das manifestações patológicas.

A Tabela 2 sintetiza as ações preventivas que a NBR 13755:2017 abordou para garantir o desempenho do revestimento externo durante a sua vida útil, se precavendo de riscos durante todo o processo de execução da fachada, desde sua concepção até a inspeção do sistema.

$1 \mathrm{MPa}$ : mega pascal (unidade de medida de tensão). 
Tabela 2: Ações preventivas adotadas pela NBR 13755:2017.

\begin{tabular}{|c|c|c|}
\hline Manifestações patológicas & Causas & Ações preventivas adotadas pela NBR 13755:2017 \\
\hline $\begin{array}{l}\text { Manifestações causadas por } \\
\text { umidade (mofo, bolor, } \\
\text { eflorescências, vesículas) }\end{array}$ & $\begin{array}{l}\text { - Infiltração } \\
\text { - Condensação } \\
\text { - Capilaridade } \\
\text { - Percolação } \\
\text { - Absorção } \\
\text { - Ausência de dreno, pingadeira } \\
\text { ou calha }\end{array}$ & $\begin{array}{l}\text { - Utilização de rejunte tipo II (mais resistente), que contribui com } \\
\text { o desempenho da cerâmica ao longo dos anos } \\
\text { - Elaboração de projeto de revestimento de fachada por } \\
\text { profissional legalmente habilitado }\end{array}$ \\
\hline Fissuras, trincas e rachaduras & $\begin{array}{l}\text { - Recalque } \\
\text { - Movimentos estruturais } \\
\text { - Esforçosão excessivos } \\
\text { - Dilatação térmica e higrométrica }\end{array}$ & $\begin{array}{l}\text { - Mistura mecânica da argamassa colante, garantindo melhor } \\
\text { - Utilização de rejunte tipo II (mais resistente), que contribui com } \\
\text { o desempenho da cerâmica ao longo dos anos } \\
\text { - Largura mínima de rejunte para placas cerâmicas e pastilhas, } \\
\text { auxiliando na absorção dos esforços atuantes na fachada } \\
\text { - Elaboração de projeto de revestimento de fachada por } \\
\text { profissional legalmente habilitado } \\
\text { - Definição das espessuras máximas e mínimas das camadas de } \\
\text { emboço da fachada, com utilização de telas de reforço padrão, } \\
\text { sempre que necessário } \\
\text { - Padronização da largura mínima das juntas de movimentação } \\
\text { (altura e fator de forma) } \\
\text { - Realização da cura úmida da argamassa (chapisco e emboço) e } \\
\text { umedecimento das juntas antes da aplicação do rejunte, } \\
\text { evitando a perda de água para o sistema }\end{array}$ \\
\hline $\begin{array}{l}\text { Descolamento do } \\
\text { revestimento }\end{array}$ & $\begin{array}{l}\text { - Movimentos estruturais } \\
\text { - Dilatação térmica } \\
\text { - Maixa aderência } \\
\text { - Ações do meinadequados } \\
\text { - Falhas de execução } \\
\text { - a Baixa rresistência do } \\
\text { revestimento }\end{array}$ & $\begin{array}{l}\text { - Utilização de argamassa colante ACIII em toda a fachada, } \\
\text { - Mistura mecânica da argamassa colante, garantindo melhor } \\
\text { - Romogeneidade em cada amassadura e durante sua produção } \\
\text { - Recomendação de dupla colagem para cerâmicas com superfície } \\
\text { de } 400 \text { a } 900 \mathrm{~cm}^{2} \text { (aplicação de argamassa colante tanto no } \\
\text { - Ubstrato quando no tardoz da cerâmica) } \\
\text { o desempenão de rejunte tipo II (mais resistente), que contribui com } \\
\text { - Largura mínima de rejunte para placas cerâmicas e pastilhas, } \\
\text { - Euxiliando na absorção dos esforços atuantes na fachada } \\
\text { profissional legalmente habilitado } \\
\text { - Definição das espessuras máximas e mínimas das camadas de } \\
\text { emboço da fachada, com utilização de telas de reforço padrão, } \\
\text { - Rempre que necessário } \\
\text { realização do painel teste para a efetuação de ensaios de } \\
\text { - Padronização da largura mínima das juntas de movimentação } \\
\text { (altura e fator de forma) } \\
\text { - Limpeza da estrutura através do desbaste da camada superficial } \\
\text { do concreto e, quando necessário, utilização do chapisco duplo, } \\
\text { com o intuito de aumentar o nível de aderência do sistema } \\
\text { - Execução do ensaio de resistência superficial para avaliação da } \\
\text { capacidade de suporte do emboço } \\
\text { - Definição da amostragem necessária para os ensaios (resistência } \\
\text { de aderência à tração e resistência superficial do emboço) } \\
\text { - Critério de avaliação do preenchimento do tardoz da cerâmica } \\
\text { com argamassa colante }\end{array}$ \\
\hline Manchas & $\begin{array}{l}\text { - Elementos construtivos } \\
\text { - Ações do vento e chuva } \\
\text { - Poluentes atmosféricos }\end{array}$ & $\begin{array}{l}\text { - Elaboração de projeto de revestimento de fachada por } \\
\text { profissional legalmente habilitado }\end{array}$ \\
\hline
\end{tabular}

Fonte: Adaptado de [13]. 
tem contribuído para fortalecer e padronizar os procedimentos de execução e inspeção de revestimentos cerâmicos de fachadas de acordo com métodos já utilizados em todo o setor da construção civil.

Segundo pesquisa, coordenada pela TECOMAT [17], em 12 empresas da Região Metropolitana de Recife, grande parte das medidas preventivas exigidas pela NBR 13755:2017 já estão sendo praticadas dentro das construtoras, conforme mostrado na Figura 6, como forma de assegurar que seus produtos e processos satisfaçam às necessidades dos usuários e às expectativas dos seus clientes, utilizando a gestão de risco como ferramenta para antecipar e prevenir possíveis falhas.

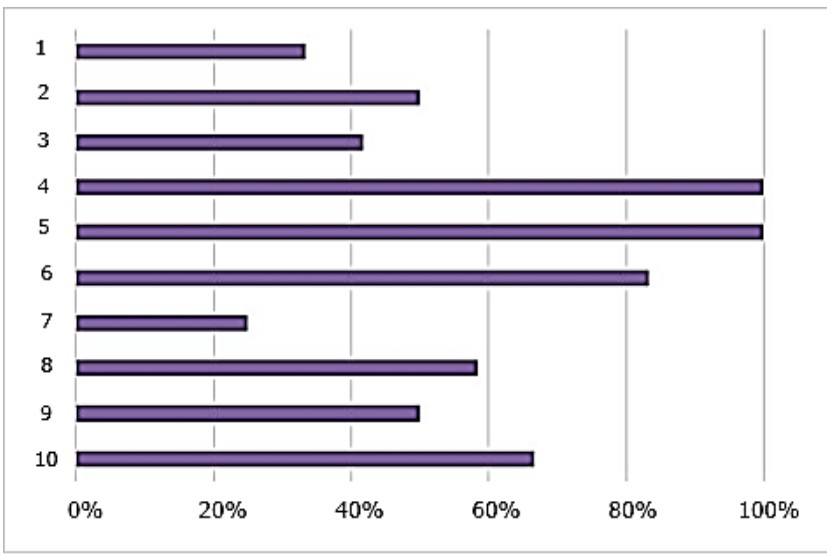

1. A argamassa colante utilizada é ACIII em todos 05 trechos da fachada?

2. A mistura da argamassa colante é feita com misturador mecânico?

3. A largura mínima utilizada para o rejunte é de $5 \mathrm{~mm}$ ?

4. A espessura mínima utilizada no emboço é de $20 \mathrm{~mm}$ ?

5. A espessura máxima utilizada no emboço é de $80 \mathrm{~mm}$ ?

6. A empresa executa um painel teste antes do início da fachada?

7. Existe a prática de execução da cura úmida no emboço?

8. Limpeza com desbaste mecânico antes da execução do chapisco?

9. Ensaios de aderência em, pelo menos, 12 pontos por pano de fachada?

10. Inspeção diária do preenchimento do tardoz das cerâmicas?

Figura 6: Pesquisa com 12 empresas da RMR para verificação ao atendimento à NBR 13755:2017.

Fonte: Adaptado de [17].

\section{CONCLUSÃO}

Diante do exposto, pode-se afirmar que a atualização mais recente da NBR 13755 (2017) foi fortemente influenciada pela mentalidade $\mathrm{e}$ gestão de risco recomendada pela ISO 9001:2015 na revisão dos seus requisitos e critérios.

Com base na abordagem das ameaças e oportunidades capazes de afetar qualquer processo de execução do revestimento externo, inclusive as manifestações patológicas mais recorrentes nas fachadas, a NBR 13755:2017 traçou ações preventivas ou potencializadoras para serem aplicadas dentro das organizações, visando mitigar as falhas e garantir 0 atendimento do desempenho proposto pelo sistema.

A aplicação da gestão de risco e de sua visão preventiva ao longo de todo o processo produtivo na versão atual desta norma, fortalece o uso da ferramenta em qualquer setor, inclusive na construção civil, sendo capaz de trazer diversos benefícios e melhorias para as construtoras a medida que elimina/reduz os riscos, aumenta a eficiência produtiva e previne prejuízos e deficiências no sistema de revestimento externo, assegurando produtos que permitam alta qualidade a clientes e consumidores. $O$ gerenciamento de risco ainda representa uma importante estratégia empresarial para o setor civil à proporção que trata problemas potenciais do negócio e os converte em oportunidades para se destacar no mercado, ganhando diferencial competitivo.

Embora a implantação dos principais requisitos exigidos pela NBR 13755:2017 já seja realidade em algumas construtoras, conforme Figura 6 , sua atualização, ocorrida em 2017, é considerada recente, e, por isso, sem muitos resultados ou estudos concretos de sua eficácia. Desta forma, recomenda-se o desenvolvimento de pesquisas mais aprofundadas no que diz respeito à efetividade dos critérios sugeridos para execução dos revestimentos externos das edificações.

Com o estudo detalhado à NBR 13755:2017, ainda pôde-se notar a falta de correlação desta norma com a NBR 15575-4:2013 (Norma de Desempenho - Parte 4: Sistemas de vedações verticais internas e externas - SVVIE), que estabelece requisitos, critérios e métodos para avaliação do desempenho de sistemas de vedações verticais internas e externas de edificações habitacionais. Sugere-se, também, a utilização da NBR 13755:2017 nas próximas revisões da norma de desempenho, com o objetivo de fomentar as diretrizes da NBR 13755 e da cultura de ações preventivas, mudando a forma de pensar e agir dos empresários e de todas as partes interessadas pertinentes. 


\section{REFERÊNCIAS}

[1] CHAVES, S.; CAMPELLO, M. A qualidade e a evolução das normas série ISO 9000. In: SIMPÓSIO DE EXCELÊNCIA EM GESTÃO E TECNOLOGIA, 13., 2016, Resende. Anais [...] Resende, RJ: AEDB, 2016. Disponível em: https://www.aedb.br/seget/arquivos/artigos16/27 224305.pdf. Acesso em: 08 set. 2018.

[2] GOMES, M. E. M. F.; BARBOSA, A. D. F. B. Sistema de gestão integrada na construção civil. Revista de Engenharia e Pesquisa Aplicada, v. 2, n. 2, 2017.

[3] LOPES, A. C. S. ; BARBIERI, J. C. A gestão de risco na ISO 9001:2015, 2016. Disponível em: https://portaldagestaoderiscos.com/casesartigos. Acesso em: 23 ago. 2018.

[4] BARBOSA, A. D. F. B. Sistema de gestão da qualidade - ISO 9001 . (Notas de aula) Pós- graduação em Gestão da Qualidade e Produtividade, Escola Politécnica de Pernambuco, Recife, 2017.

[5] DA SILVA, T. T. L.; BARBOSA, A. D. F. B. Evolução da norma ISO 9001: uma análise comparativa. Revista de Engenharia e Pesquisa Aplicada, v. 2, n. 4, 2017.

[6] ASSOCIAÇÃO BRASILEIRA DE NORMAS TÉCNICAS. NBR 31000. Gestão de riscos princípios e diretrizes. Rio de Janeiro: ABNT, 2009.

[7] ASSOCIAÇÃO BRASILEIRA DE NORMAS TÉCNICAS. NBR ISO 9001 . Sistemas de gestão da qualidade - requisitos. Rio de Janeiro: ABNT, 2015.

[8] JUST, A; FRANCO, L. S. Descolamentos dos revestimentos cerâmicos de fachada na cidade do Recife. São Paulo: EPUSP, 2001.

[9] PEZZATO, L. M. Patologias no sistema de revestimento cerâmico: um estudo de caso em fachadas. 2010. Dissertação (Mestrado em Arquitetura e Urbanismo) - Escola de Engenharia de São Carlos, Universidade de São Paulo, São Carlos, 2010. f. 23-162.

[10] PACHECO, C. P.; VIEIRA, G. L. Análise quantitativa e qualitativa da degradação das fachadas com revestimento cerâmico. Cerâmica, v. 63, n. 368, p. 432-445, 2017. Disponível em: <http://dx.doi.org/10.1590/0366-

69132017633682156 >. Acesso em 10 set. 2018.

[11] ESQUÍVEL, J. f. T.; SIMÕES, J. R. L.
Avaliação do uso de revestimentos cerâmicos de fachada em edifícios residenciais multifamiliares em São Paulo: estudo de caso região sul. 2001. Dissertação de mestrado. Faculdade de Arquitetura e Urbanismo da Universidade de São Paulo, São Paulo, 2001. f.8-74.

[12] ROSCOE, M. T; JUNIOR, A. N. D. C. Patologias em revestimento cerâmico de fachada. 2008. Monografia (Especialização em Engenharia Civil) - Escola de Engenharia da Universidade Federal de Minas Gerais. Belo Horizonte, 2008. Disponível em: http://hdl.handle.net/1843/BUOS-9A4JS4. Acesso em: 08 set 2018 .

[13] PIRES, J. M.; DA SILVA, D. L. ; RABBANI, E. R. K.; DO NASCIMENTO, I. M. S. Análise das manifestações patológicas presentes nas fachadas de um casario tombado no município de Pesqueira-PE. Revista de Engenharia e Pesquisa Aplicada, v. 2, n. 3, 2017.

[14] ASSOCIAÇÃO BRASILEIRA DE NORMAS TÉCNICAS. NBR 13755. Revestimento de paredes externas e fachadas com placas cerâmicas e com utilização de argamassa colante - procedimento. Rio de Janeiro: ABNT, 1996.

[15] ALTERAÇÕES NBR 13755 - módulo 2 materiais. [s. I.: s. n.], 2018. 1 vídeo (5 min). Publicado pelo canal Tecomat Engenharia. Disponível em:

https://www.youtube.com/watch?v=jJPKt2S gjNU Acesso em: 08 set. 2018.

ALTERAÇÕES NBR 13755 - módulo 1 - projetos. [s. I.: s. n.], 2018. 1 vídeo (6 min 36s). Publicado pelo canal Tecomat Engenharia. Disponível em: https://www. youtube. com/watch?v=bAR5eagI2c Acesso em: 08 set. 2018.

ALTERAÇÕES NBR 13755 - módulo 3 revestimento cerâmico. [s. I.: s. n.], 2018. 1 vídeo (6 min $7 \mathrm{~s}$ ). Publicado pelo canal Tecomat Engenharia. Disponível em: https://www. youtube. $\mathrm{com} /$ watch?v=4aHIn $1 \mathrm{nAPo}$ 8. Acesso em: 08 set. 2018.

ALTERAÇÕES NBR 13755 - módulo 4 - inspeção e controle. [s. I.: s. n.], 2018. 1 vídeo (5 min 25s). Publicado pelo canal Tecomat Engenharia. Disponível em: https://www.youtube.com/watch?v=EZq_rVEQpe Y. Acesso em: 08 set. 2018.

[16] ASSOCIAÇÃO BRASILEIRA DE NORMAS TÉCNICAS. NBR 13755. Revestimentos cerâmicos de fachadas e paredes externas 
com utilização de argamassa colante projeto, execução, inspeção e aceitação procedimento. Rio de Janeiro: ABNT, 2017.

[17] JUST, A. Pesquisa de atendimento à NBR 13755:2017 em 12 empresas da RMR.

(Notas de aula) - Graduação em Engenharia Civil da Escola Politécnica de Pernambuco, Recife, 2018. 